\title{
Effect of Intermittent Pneumatic Compression on Functional Level and Quality of Life in Community-Dwelling Older Adults with Limited Ambulation Due to Leg Pain: A Randomized Controlled Trial
}

\author{
Weerasinghe Mudiyanselage Sujeewa Weerasinghe1, \\ Thunpaththu Mudiyanselage Upul Sanjeewa Thunpaththu', \\ Weerasinghe Mudiyanselage Sandali Anjana Weerasinghe ${ }^{1,3}$, \\ Weerasinghe Mudiyanselage Shalindu Thushen Weerasinghe ${ }^{1}$, \\ Pahala Walpola Gamarallage Shirani Walpola ${ }^{1}$, \\ Dissanayaka Mudiyanselage Tharanga Padmini Dissanayaka ${ }^{4}$, Angelo Karunaratne ${ }^{5}$ \\ ${ }^{1}$ Physio Life Care (Physical Medicine, Rehabilitation and Research), Ruwanwella, Sri Lanka \\ ${ }^{2}$ National Hospital of Sri Lanka, Colombo, Sri Lanka \\ ${ }^{3}$ Rajarata University of Sri Lank, Mihintale, Sri Lanka \\ ${ }^{4}$ National Secretariat for Early Childhood Development, Colombo, Sri Lanka \\ ${ }^{5}$ Department of Mechanical Engineering, University of Moratuwa, Moratuwa, Sri Lanka \\ Email: weerasinghe.sujeewa@gmail.com
}

How to cite this paper: Weerasinghe, W.M.S., Thunpaththu, T.M.U.S., Weerasinghe, W.M.S.A., Weerasinghe, W.M.S.T., Walpola, P.W.G.S., Dissanayaka, D.M.T.P. and Karunaratne, A. (2021) Effect of Intermittent Pneumatic Compression on Functional Level and Quality of Life in Community-Dwelling Older Adults with Limited Ambulation Due to Leg Pain: A Randomized Controlled Trial. Health, 13, 1145-1169.

https://doi.org/10.4236/health.2021.131008 $\underline{5}$

Received: August 4, 2021

Accepted: October 26, 2021

Published: October 29, 2021

\begin{abstract}
Background and Purpose: Walking difficulties are defined as any reduction in speed, balance, or change of gait, causing limited ambulation. These difficulties are a common problem in older adults and may greatly affect their quality of life (QOL) and restrict their personal independence and participation. This study aimed to determine the effect of intermittent pneumatic compression (IPC) on lower leg pain, walking capacity, functional mobility, ankle range of motion (AROM), and QOL of community-dwelling older people with walking difficulties. Methods: In this randomized controlled trial, 34 eligible participants with self-reported lower limb pain and limited ambulation were randomized either to the intermittent pneumatic compression intervention group (IPCIG) or static compression control group (SCCG). The IPCIG and SCCG were trained to receive IPC and SC respectively for both lower legs and instructed to continue the application independently at home for $15 \mathrm{mi}-$ nutes per session, 2 sessions a day, 7 days per week for 4 weeks independently at the home. Outcome measures of lower leg pain, AROM, walking capacity, and functional mobility were assessed at baseline and at the first, second,
\end{abstract}


Copyright $\odot 2021$ by author(s) and Scientific Research Publishing Inc. This work is licensed under the Creative Commons Attribution International License (CC BY 4.0).

http://creativecommons.org/licenses/by/4.0/

Open Access third, and fourth weeks after randomization. Quality of life was assessed at baseline and immediately after the intervention. Results and Discussion: IPCIG showed a more significant improvement compared to the SCCG at the post-interventional stage for QOL and all the subscales. The findings show that " $80 \%$ improved QOL" is $53 \%$ higher with the application of IPC than with SC for 4 weeks. The IPCIG showed a more significant improvement in the 6-minute walk test (6 MWT) at the third and fourth weeks compared to the SCCG. A pairwise comparison of mean values of 6 MWT over 4 weeks within the IPCIG showed a significant difference between all the weeks. Pairwise comparisons between groups at each time point showed that the IPCIG showed a more significant improvement in the timed up and go (TUG) test at the third and fourth weeks compared to the SCCG. Pairwise comparison of mean values of TUG test within the IPCIG showed a significant difference over 4 weeks, except between the second and third weeks, fourth week, and third and fourth weeks. The IPCIG showed a more significant improvement in lower leg pain between all weeks except the first week compared to the SCCG. Pairwise comparison of mean values of lower leg pain over 4 weeks within the IPCIG showed a significant difference among all weekly outcomes except between 1 and 2 weeks. The IPCIG showed a more significant improvement in left and right ankle dorsiflexion ROM at the third and fourth weeks compared to the SCCG. Conclusions: The IPC was effective in reducing lower leg pain and increasing the AROM and improving the walking capacity, functional mobility level, and QOL of community-dwelling older people with walking disabilities. Walking disability in old age is a common condition requiring physical therapy. Intermittent pneumatic compression can be used as a physical therapy modality for this patient group.

\section{Keywords}

Intermittent Pneumatic Compression, Functional Level, Quality of Life, Older Adults, Limited Ambulation, Leg Pain

\section{Introduction}

Walking is a common activity of daily living and a significantly complex task. It involves all levels of the nervous system and many parts of the musculoskeletal and cardiorespiratory systems [1]. Walking difficulties can be defined as any reduction of speed or balance or change in gait, causing limited ambulation. These difficulties are a common problem in older adults [2] [3] [4] [5] [6]. Walking disability develops gradually, and many older adults are referred (or self-refer) to a geriatric specialist because of their mobility problems [1]. The prevalence of gait and balance disorders markedly increases with age, from approximately $10 \%$ between the ages of 60 and 69 years to more than $60 \%$ in those aged over 80 years. 7 gait impairments and walking difficulties may greatly affect the quality of life (QOL) of older adults [7] and restrict the personal independence of those affected [2] [3] [4] [5] [6]. 
The number of older individuals is increasing rapidly worldwide. By 2050, the world's population aged 60 years and older is expected to reach 2 billion, up from 900 million in 2015. Aging may be a reason a person experiences "care dependence," which arises when the functional ability has fallen to a point where an individual is no longer able to perform the basic tasks necessary for daily life without the assistance of others [8]. Among other reasons, one of the major reasons for older adults' dependency is their difficulty in walking. In the context of development and economy, old-age dependence is generally portrayed as a negative state, resulting in the transfer of benefits from younger, presumably more productive generations to older ones. This worldwide problem can be addressed if the state of dependency among older adults can be reduced by preventing walking difficulties and improving walking ability, functional level, QOL, and level of participation.

Engaging in physical activity across the life course has many benefits, including increased longevity. For example, a recent pooled analysis of large longitudinal studies has found that people who engaged in 150 minutes per week of physical activity at moderate intensity had a $31 \%$ reduction in mortality compared with those who were less active. The benefit was greatest in those older than 60 years [9]. Physical activity has multiple other benefits in older age. These include improving physical and mental capacities (e.g., by maintaining muscle strength and cognitive function, reducing anxiety and depression, and improving self-esteem), preventing disease and reducing risk (e.g., of coronary heart disease, diabetes, and stroke), and improving social outcomes (e.g., by increasing community involvement and maintaining social networks and intergenerational links). These benefits are substantial. For example, both cross-sectional and longitudinal studies have suggested a 50\% reduction in the relative risk of developing functional limitations among individuals performing regular and moderate-intensity physical activity [10] [11]. Physical activity also appears to preserve, and may even improve, cognitive function in people without dementia [10] [12], reducing cognitive decline by approximately one-third [13]. In addition, physical activity protects against some of the most important health conditions in older adults. Physical inactivity may account for up to $20 \%$ of the population-attributable risk of dementia, and it has been estimated that 10 million new cases globally might be avoided each year if older adults meet the recommendations for physical activity [14]. Similarly, stroke causes some of the greatest burdens of disease in older age, and moderate physical activity may reduce the risk by $11 \%-15 \%$, and vigorous physical activity has even greater benefits, reducing the risk by $19 \%-22 \%$ [15]. Walking is the most commonly used aerobic physical activity and the main mode of aerobic exercise among older adults. Therefore, improving the walking ability of older adults would be an important intervention to achieve most of the abovementioned health and social benefits. It is difficult to address these issues without sufficient functional levels. Interventions to improve walking have historically been multifactorial. Commonly used exercise interventions in older adults include muscle strengthening, power and 
resistance training, and coordination training [16]. However, these multifactorial impairment-based programs have resulted in only modest improvements in walking (e.g., an approximate 5\% increase in gait speed, with a range of $0 \%-$ 16\%) [17]-[28]. Therefore, there is a need to identify interventions that may be useful in improving walking capacity, functional level, and QOL and that can be applied simply to the older adult population.

Intermittent pneumatic compression (IPC) is an emerging modality of compression therapy that uses a mechanical device to deliver compression to limbs. An Intermittent pneumatic compression (IPC) device is composed of an inflatable garment consisting of one or more pressure compartments that wrap around the limb or the intended body part, and a pneumatic pump that fills the garment with compressed air. The garment is intermittently inflated and deflated with cycle times and pressures that vary between devices [29]. IPC is a possible solution for improving walking capacity, functional level, and QOL that can be applied simply to the older adult population. One of the main causes of limited ambulation in older adults is lower leg pain, which is associated with swelling of the lower leg, ankle, and foot, muscular spasms of the lower leg and foot, and reduction of the ankle range of motion (AROM). Massage has a positive effect on reducing the above factors and, hence, lowers leg pain [30] [31]. The application of IPC provides a massage effect for the muscles of the lower leg, which would alleviate lower leg pain and associated factors. Static compression garments are a conventional method used to reduce leg pain and associated factors, including swelling of the calf, ankle, and foot and muscular spasms of the calf and foot. However, it has been identified that the use of compression garments is less effective [32].

However, studies investigating the effects of IPC application to the lower leg are scarce. Some studies have reported the effect of pneumatic compression on walking capacity and QOL of patients with intermittent claudication [33] Therefore, an intervention such as IPC to the lower leg muscles, which may optimize walking capacity, functional mobility, and QOL, is a logical intervention for older persons with walking difficulties. However, the effect of IPC on the lower leg muscles at the functional level and QOL in community-dwelling older adults has not been investigated. Therefore, this study aimed to investigate the effect of IPC application on walking capacity, functional mobility, and QOL in community-dwelling older people with walking disabilities. The effect of IPC on lower leg pain and AROM was also studied.

\section{Methods}

\subsection{Design Overview}

This study was a randomized controlled trial. Ethical approval was obtained from the Ethics Review Committee of the Chartered Society of Physiotherapy, Sri Lanka (CSPERC 003/2019). Sample size was decided based on previous studies as there have been no studies conducted in this specific area. [29] [30] [31]. 
The protocol was registered in the clinical trial registry of the World Disability and Rehabilitation Professionals' Association (WDRPACTR 2019/001).

\subsection{Study Setting}

This study was conducted at three medical offices in the health areas of Kegalle District in Sri Lanka. Participants were screened and enrolled in August, and the study was completed in September 2019. Individuals aged $>60$ years with selfreported lower leg pain and walking difficulties were recruited.

The inclusion criteria were as follows: patients (1) with self-reported lower limb pain and walking difficulty; (2) currently seeking care for pain and walking difficulties; (3) aged > 60 years; and (4) able to understand instructions The exclusion criterion were as follows: (1) patients with acute pulmonary edema; (2) acute thrombophlebitis; (3) acute congestive cardiac failure; (4) acute infections; (5) deep vein thrombosis; (6) episodes of pulmonary embolism; (6) wounds, lesions, or tumors at or near the site of application, where increased venous and lymphatic returns are undesirable; (7) bone fractures or dislocations at or near the application site; (8) pregnant and postnatal women; (9) patients using implantable equipment, such as cardiac pacemakers; (10) patients with skeletal injuries and diseases; (11) patients with cancer; (12) patients with high blood pressure or abnormal blood pressure; (13) patients with severe atherosclerosis or other ischemic vascular diseases; (14) patients with severe congestive cardiac failure; (15) patients with existing pulmonary embolism; (16) patients with extreme deformity of the limbs limited to gangrene, untreated or infected wounds, recent skin grafts, and dermatitis; (17) patients with known malignancy in the legs; (18) patients with limb infections, including cellulitis, not receiving antibiotic treatment; and (19) patients with lymphangiosarcoma.

Four recruitment strategies were used to optimize the participation: disseminating recruitment notices; obtaining the information of potential participants through public health midwives, public health inspectors, and social service officers; displaying recruitment notices in public places; and using a consecutive sampling method.

\subsection{Randomization and Interventions}

Participants volunteered and were screened to determine their eligibility, based on the inclusion criteria described above, by an independent investigator. Once the inclusion criteria were met, the participants were enrolled with their signed informed consent form. Participants were randomly assigned to the intermittent pneumatic compression intervention group (IPCIG) or static compression control group (SCCG) using a computer-generated randomization table. All of the individual allocations were placed in sealed envelopes. Enrollment, randomization, and generation of the random allocation were performed by independent investigators who did not participate in the outcome measures and data collection. 


\subsection{Intermittent Pneumatic Compression Intervention Group}

Participants in the IPCIG received instructions and were trained by a physiotherapist on the application of IPC to both the lower legs for 15 minutes per session, twice a day, 7 days per week for 4 weeks using the Spryng ${ }^{\text {TM }}$ Calf Wrap (Model No: SPRCW1 $)^{1}$, an IPC device. Low compression intensity of $30 \mathrm{mmHg}-50$ $\mathrm{mmHg}$ and graduated compression (wavetec ${ }^{\mathrm{TM}}$ ) pattern were used for the IPC, which was performed in a seated position (Appendix 1). In the wavetec ${ }^{\mathrm{TM}}$ compression profile, the lower calf is initially compressed to a peak pressure value. Before the lower calf reaches its peak value, the mid-calf region is compressed to its peak pressure, which is lower than the lower calf pressure. Similarly, the top calf begins to be compressed before the mid-calf reaches its peak value. Narrowing of the leg veins is considered a basic mechanism of compression therapy. In the upright (sitting and standing) position, an external pressure of approximately 30 to $40 \mathrm{mmHg}$ is necessary to narrow the leg veins [34]. According to the manufacturer's specifications, the pressure range produced by the IPC device is $30 \mathrm{mmHg}-50 \mathrm{mmHg}$; therefore, this pressure range is sufficient to produce effects on the lower limbs, which are in a dependent position. This study aimed to assess the use of IPC devices during day-to-day activities without disturbing daily activities such as watching TV and writing. Therefore, we aimed to test the efficacy of the IPC device in a seated position compared to the use of a static compression garment in a seated position. Therefore, we used the seated position with the legs in a dependent position.

Each participant in the IPCIG was trained on the application of the IPC with the IPC device at baseline. The training included the correct application of the IPC, safety measures that should be taken when using the IPC, and technical operations involved in the application of the IPC including switching and adjustment of mode and intensity. The necessary IPC devices were provided. The accuracy of the self-application of the IPC was supervised by home visits on the second, fourth, and eighth days of the commencement of the intervention, and further training was provided if necessary. Static compression was not applied to the IPCIG.

\subsection{Static Compression Control Group}

The control intervention was the application of static compression to both lower legs for 15 minutes per session, twice a day, 7 days per week for 4 weeks with the Tubigrip $^{\oplus}$ multi-purpose tubular support bandage ${ }^{2}$. The pressure ranges produced by this static compression garment based on the limb circumference are $20-30 \mathrm{mmHg}, 10-20 \mathrm{mmHg}$, and $5-15 \mathrm{mmHg}$, according to the manufacturer's specifications. Narrowing of the leg veins is considered the basic mechanism of compression therapy. In the upright (sitting and standing) position, an external pressure of approximately 30 to $40 \mathrm{mmHg}$ is necessary to narrow the leg ${ }^{1}$ MAS Design Inc., New York, NY, USA.

${ }^{2}$ Mölnlycke Health Care AB, Gamlestadsvägen 3 C, SE-402 52 Göteborg, Sweden. 
veins [34]. Therefore, this pressure range is insufficient to produce effects on the lower limbs, which are in a dependent position.

The intervention was performed in a seated position (Appendix 1). Each participant in the SCCG was trained on the application of static compression with a conventional compression garment at baseline. The necessary static compression garments were provided. The accurate application was supervised at the second, fourth, and eighth days of the commencement of the intervention, and further training was provided if necessary. All instructions and training were delivered by experienced physiotherapists, who were trained in the standard protocols on the provision of IPC and static compression interventions, in managing older adults.

\subsection{Outcomes and Follow-Up}

All measurements were conducted by investigators who were trained to perform standardized assessment procedures and were blinded to group assignment. Outcome measures for each participant were assessed by the same investigator at the baseline and at the completion of the first, second, and third weeks of the commencement and end of the 4-week intervention. We used the International Classification of Functioning, Disability and Health (ICF) model of the World Health Organization as a theoretical framework for selecting outcome measures [35]. The primary outcome measure was QOL, which was assessed using the Short Form 36 Health Survey Questionnaire (SF-36) [32]. It addressed the ICF domain of participation. The SF-36 has been shown to be valid and reliable in assessing the quality of life of community-dwelling older adults [36]. The instrument consists of 36 questions that require respondents to rate items related to eight conceptual areas, including general health, ability to perform certain physical function, level of pain, emotional state, role limitations due to physical health, role limitations due to emotional problems, social functioning and energy/fatigue.

Secondary outcome measures assessing the ICF domain of activities included walking capacity and functional mobility as assessed by the 6-minute walk test (6 MWT) and the timed up and go (TUG) test, respectively. The 6 MWT has shown valid and excellent test-retest reliability $(r=0.95)$ for the mobility-related function in older adults [37]. The minimal detectable change for 6 MWT was 20 $\mathrm{m}$ [38]. The TUG test has shown valid and excellent test-retest reliability (intraclass correlation coefficient $=0.88$ for usual gait speed) in older adults [39]. The minimal detectable change for 6 MWT was $2.08 \mathrm{~s}$ for TUG test [40]. Secondary outcome measures within the ICF domain of body function and structures included the numerical pain rating scale (NPRS), AROM, dorsiflexion, and plantarflexion. NPRS is a reliable and valid pain intensity scale used when assessing pain experienced by older adults [41]. It involves asking patients to rate their pain from 0 to 10, with 0 representing one end of the pain continuum (e.g., no pain) and 10 representing the other extreme of pain intensity (e.g., pain as 
bad as it could be) [42]. Measurements of dorsiflexion and plantarflexion of the bilateral ankle joints were obtained with a 360-degree EMI diagnostic goniometer $^{3}$. The goniometer was calibrated in 1-degree increments. Sociodemographic data were collected using an interviewer-administered questionnaire.

\subsection{Adverse Events and Adherence}

All participants in both groups were instructed to complete a tick-box diary to record compliance with their home intervention. The participants' satisfaction and motivation to receive IPC and static compression were measured using a 10-point numeric rating scale. Any adverse event, unexpected occurrences, and identified potential risks during the intervention were recorded, in both groups to assess the safety of application of IPC and static compression to the lower legs with dynamic compression garments and static compression garments, respectively.

\subsection{Withdrawal Criteria and Safety Considerations}

Participants were provided with an adequate amount of time to consider their participation in the trial and an opportunity to ask questions. If the patient decided to participate in the study, they were instructed to provide written consent, which was then countersigned by the investigator. All participants were free to withdraw from the study at any time. Intervention was performed under the supervision of the physiotherapists, and participants were assessed before, during, and after the intervention for any adverse events. They were given assurances throughout the study, and their data were kept confidential. The research personnel involved worked closely with the participants to monitor the occurrence of any untoward effects. The Adverse Event Reporting Form of the Ethics Review Committee of The Chartered Society of Physiotherapy, Sri Lanka, was used for this purpose. The involvement of the research team and the aforementioned monitoring and safety procedures were specifically designed to minimize any potential risks to the physical health of the participants. A medical officer examined all of the participants before and after the intervention.

\subsection{Role of Funding Source}

This study was funded by MAS Holdings (Sri Lanka). The funds were used for study-related costs including human resources and equipment. They also provided the IPC devices and static compression garments used in this study. This funding agency did not play any role in the study design, data collection, analyses and interpretation of data, writing of the manuscript, or the decision to submit the manuscript for publication.

\subsection{Statistical Analyses}

Descriptive analysis was conducted to find the distribution and level of normali- 
ty of data in both groups at the baseline and weekly until four weeks. Variation of seven dependent variables; walking capacity (6 MWT), functional mobility (TUG ), pain in lower leg, and AROM (right and left, dorsiflexion and plantarflexion) were analyzed with the time; baseline, first, second, third and fourth week respectively and between two groups using two way repeated measure MANOVA. Univariate analysis using one way repeated measure ANOVA was conducted to compare variations within the groups with the time separately for each dependent variable as the MANOVA test results got significant at 5\% significant level with $95 \%$ CI. Since there are 5 time points, 10 pairs were compared within one group for one variable. Hence total 140 pairs for all the variables were analyzed at 0.00036 significant levels based on Bonferroni correction for multiple pairwise comparisons (0.05/140). Between-group comparisons at each time for each variable were conducted $(2 \times 7 \times 5)$, at 0.00071 significant level based on the Bonferroni correction (0.05/70). Quality of life was analyzed separately using two way repeated measures MANOVA at the baseline and at the completion of four weeks of intervention according to eight sub components as well as a whole. Univariate analysis was conducted to compare variations within the groups with the time separately for each dependent variable as the MANOVA test results got significant at $5 \%$ significant level with $95 \%$ CI. Since there are 2 time points, 09 pairs were compared within one group. Hence total 18 pairs were analyzed at 0.0027 significant level based on Bonferroni correction for multiple pairwise comparison (0.05/18). Between-group comparisons at each time for each variable were conducted $(2 \times 9 \times 2)$, at 0.00138 significant level based on the Bonferroni correction (0.05/36). Risk difference and number needed to treat was calculated end of the trail for QOL to find the effectiveness of the application of IPC and more than $80 \%$ improvement considered as the cutoff mark.

\section{Results}

Figure 1 shows the consort flow diagram. Among the 64 individuals screened, a total of 34 participants were eligible for randomization and gave written informed consent. Table 1 summarizes the baseline demographics and clinical characteristics for the 34 randomized participants, stratified by intervention assignment. No statistically significant baseline differences were found between the groups except for general health component of the SF-36 (Table 1). The completion rate of the study was $100 \%$. All participants returned their diaries on performance of intervention at home and all the participants of both groups had completed all the home intervention sessions assigned. Scores for satisfaction and motivation of the intervention group on 10 point scales were 10 and 10 respectively. There were no adverse events reported in both groups.

\subsection{Primary Outcome}

There is a significant interaction effect between time, group and dependent variables in the intervention at 5\% significant level and 95\% CI with higher level of 
Table 1. Participant baseline demographic, clinical characteristics and outcome measures of intervention and control groups ${ }^{\mathrm{a}}(\mathrm{N}=34)$.

\begin{tabular}{|c|c|c|c|}
\hline Variable & $\begin{array}{l}\text { Intermittent pneumatic } \\
\text { compression intervention } \\
\text { group }(\mathrm{N}=17) \text { Mean }(\mathrm{Sd})\end{array}$ & $\begin{array}{c}\text { Static Compression } \\
\text { Control Group }(\mathrm{N}=17) \\
\text { Mean }(\mathrm{Sd})\end{array}$ & $P$ value \\
\hline \multicolumn{4}{|l|}{ Demographics } \\
\hline Gender-Male: Female & $6 / 11$ & $6 / 11$ & \\
\hline Age (Years) & $68.24(6.320)$ & $68.88(7.017)$ & 0.779 \\
\hline Weight (Kg) & $59.18(6.327)$ & $60.65(10.093)$ & 0.614 \\
\hline Height $(\mathrm{cm})$ & $154.71(8.417)$ & $153.47(9.824)$ & 0.696 \\
\hline \multicolumn{4}{|l|}{ Clinical characteristics } \\
\hline BMI $\left(\mathrm{Kg} / \mathrm{m}^{2}\right)$ & 24.9976 & 26.0149 & 0.528 \\
\hline Systolic BP (Hg/mm) & $129.76(9.725)$ & $123.71(11.957)$ & 0.115 \\
\hline Diastolic BP $(\mathrm{Hg} / \mathrm{mm})$ & $71.71(9.012)$ & $71(10.863)$ & 0.838 \\
\hline HR (pulse/min) & $71.47(9.335)$ & $73.47(12.526)$ & 0.601 \\
\hline $\mathrm{RR}$ (per min) & $27(2.828)$ & $27.06(3.799)$ & 0.959 \\
\hline \multicolumn{4}{|l|}{ Outcome Measures } \\
\hline Pain in lower leg & $7.65(1.539)$ & $7.12(1.965)$ & 0.389 \\
\hline TUGS & $17.6518(3.26368)$ & $16.7900(3.32301)$ & 0.451 \\
\hline $6 \mathrm{MWT}$ & $293.82(48.332)$ & $320.59(83.120)$ & 0.262 \\
\hline \multicolumn{4}{|l|}{ SF-36 subscales } \\
\hline General Health & $29.87(18.071)$ & $43.31(15.406)$ & 0.026 \\
\hline Physical Function & $40.88(19.704)$ & $45.59(18.865)$ & 0.482 \\
\hline $\begin{array}{c}\text { Role limitations } \\
\text { due to physical health }\end{array}$ & $8.82(24.908)$ & $13.24(33.211)$ & 0.664 \\
\hline $\begin{array}{l}\text { Role limitations due to } \\
\text { emotional problems }\end{array}$ & $31.37(46.354)$ & $19.12(39.061)$ & 0.411 \\
\hline Social functioning & $63.24(16.812)$ & $57.29(22.547)$ & 0.391 \\
\hline Bodily Pain & $41.32(27.615)$ & $44.41(33.675)$ & 0.772 \\
\hline Energy/Fatigue & $50.81(15.416)$ & $54.12(22.724)$ & 0.623 \\
\hline Emotional well-being & $61.71(13.855)$ & $59.29(12.509)$ & 0.598 \\
\hline QOL & $41.00(9.863)$ & $42.05(17.176)$ & 0.829 \\
\hline \multicolumn{4}{|l|}{ Ankle Range of Motion } \\
\hline L. dorsiflexion & $6.59(3.411)$ & $5.88(5.372)$ & 0.651 \\
\hline L. plantar flexion & $20.59(11.576)$ & $23.24(11.172)$ & 0.502 \\
\hline R. dorsiflexion & $7.65(5.623)$ & $5.88(5.372)$ & 0.356 \\
\hline R. plantar flexion & 22.35 (11.197) & $23.82(10.973)$ & 0.701 \\
\hline
\end{tabular}




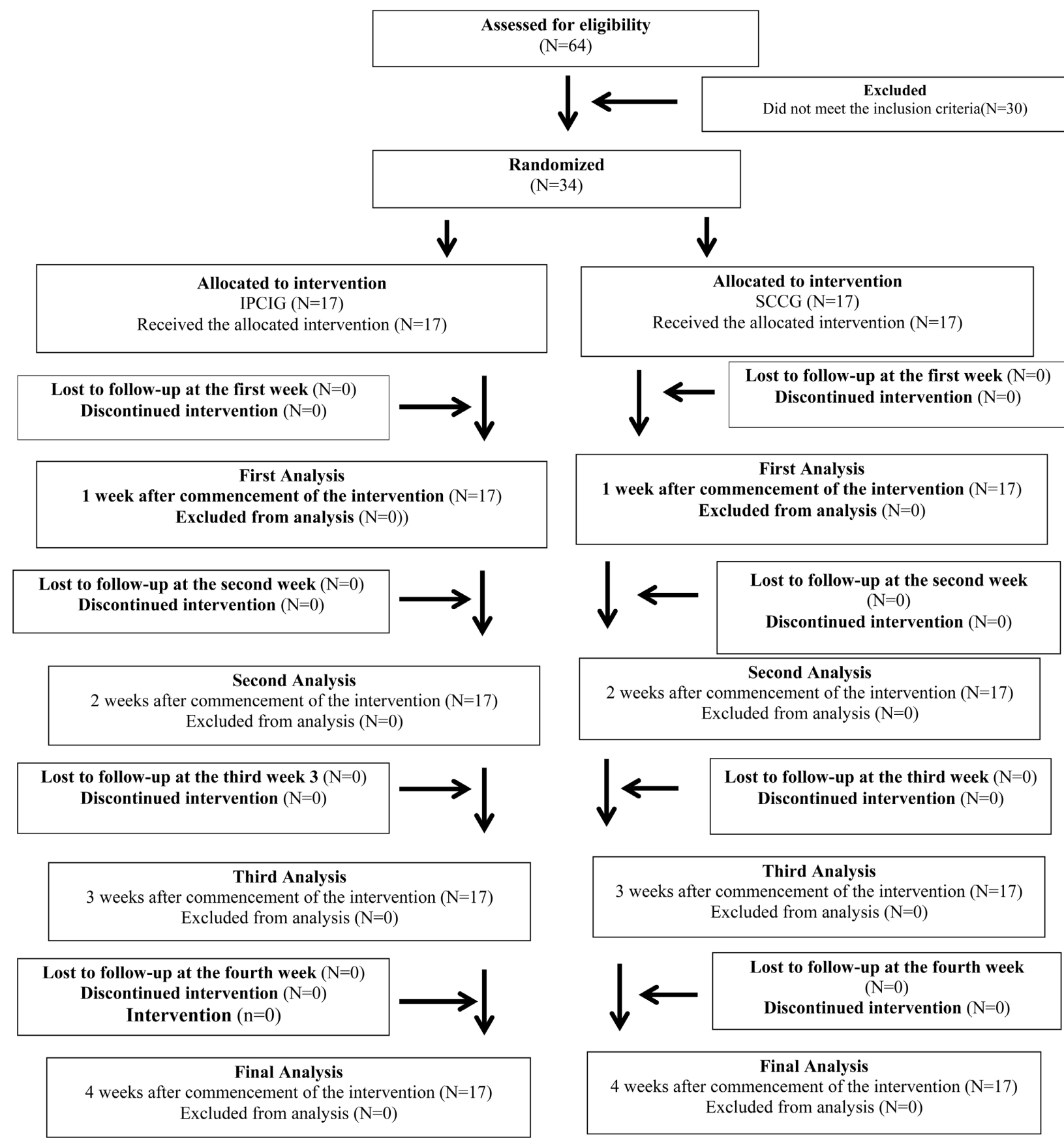

Figure 1. CONSORT flow diagram for the Enhancing functional level and quality of life of community-dwelling older people with walking difficulties through intermittent pneumatic compression Study (IPCIG = Intermittent pneumatic compression intervention group; SCCG = Static Compression Control Group).

observed power in respect to QOL outcomes. In addition to that there is a significant difference between 2 time points as well as between two experimental groups relation to nine dependent variables of QOL at 5\% significant level and 95\% CI with higher level of observed power (Table 2). Pairwise comparison was carried out to compare between the groups and time for all the dependent variables of QOL as the multivariate test showed a significant result. There is a 
Table 2. Two way RM MANOVA analysis of outcomes.

\begin{tabular}{cccc}
\hline Outcome Variables & Main effects and interactions & P value & Observed power \\
\hline & Time ${ }^{*}$ Outcomes ${ }^{*}$ Group & 0.041 & 0.773 \\
Primary outcomes & Time & 0.000 & 1.000 \\
& Group & 0.000 & 0.970 \\
& Time ${ }^{*}$ Group & 0.000 & 1.000 \\
\hline \multirow{2}{*}{ Secondary outcomes } & Time $^{*}$ Outcomes ${ }^{*}$ Group & 0.000 & 1.000 \\
& Time & 0.000 & 1.000 \\
& Group & 0.001 & 0.937 \\
& Time ${ }^{*}$ Group & 0.000 & 1.000 \\
\hline
\end{tabular}

significant improvement in IPCIG compared to SCCG at post interventional stage for $Q O L(P=0.00000)$, and all the sub scales, general health $(P=0.00088)$, physical function $(\mathrm{P}=0.00009)$, role limitations due to physical health $(\mathrm{P}=$ $0.00000)$, role limitations due to emotional problems $(P=0.00000)$, social functioning $(P=0.00099)$, bodily pain $(P=0.00006)$, energy $(P=0.00028)$ and emotional wellbeing $(\mathrm{P}=0.00093)$. (Table 3, Figure 2(a)). Pairwise comparison of mean values within the IPCIG at baseline and post intervention shows that there is a significant difference $(\mathrm{P} \leq 0.0027)$ among the QOL and 8 sub scales of SF-36 except social functioning subscale and there is no significant difference $(\mathrm{P} \geq$ 0.0027) in Pairwise comparison of mean values within the SCCG at baseline and post intervention (Table 4).

\subsection{Secondary Outcomes}

There is a significant interaction effect between time, group and dependent variables in the intervention at 5\% significant level and 95\% CI with higher level of observed power. In addition to that there is a significant difference between 5 time points as well as between two experimental groups relation to seven dependent variables; walking capacity (6 MWT), functional mobility (TUG), pain in lower leg, and AROM (right and left dorsiflexion and plantarflexion) at 5\% significant level and 95\% CI with higher level of observed power (Table 2). Pairwise comparison between groups at each time point shows that there is a significant improvement in 6 MWT of IPCIG at 3rd and 4th week comparatively to SCCG ( $\mathrm{P} \leq$ 0.00071) (Table 5, Figure 2(b)). Pairwise comparison of mean values of 6 MWT over 4 weeks within IPCIG shows a significant difference between baseline and all 4 weeks as well as between 3rd week and 4th week (Table 7). Further there is a significant difference of 6 MWT $(\mathrm{P} \leq 0.00036)$ within IPCIG between baseline and 1st week assessment (Table 7). This shows that even 1 week initial application of intervention is effective in improving walking capacity.

Pairwise comparison between groups at each time point shows that there is a significant improvement in TUG of IPCIG at 3rd and 4th week comparatively to 


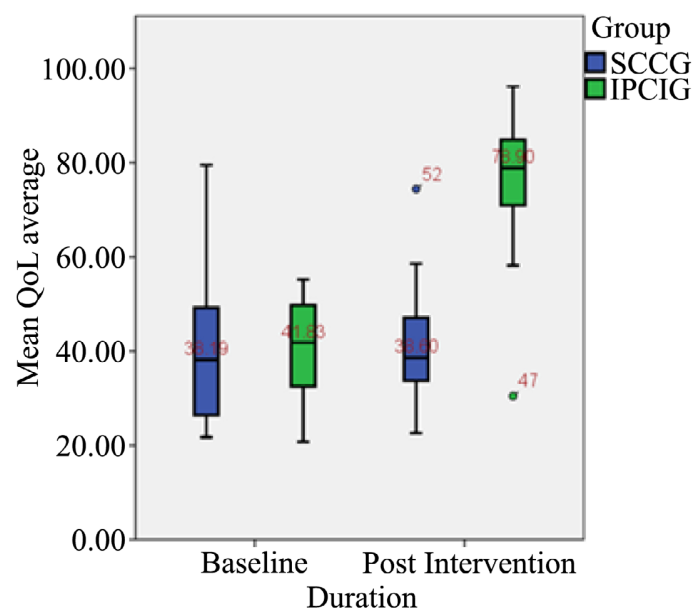

(a)

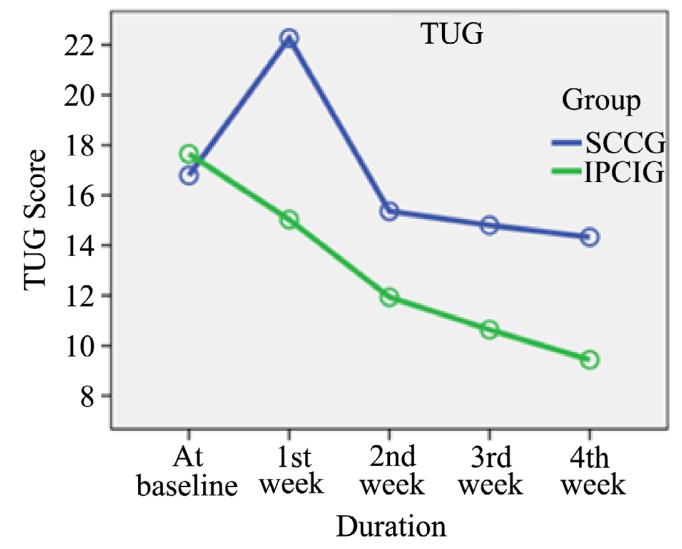

(c)

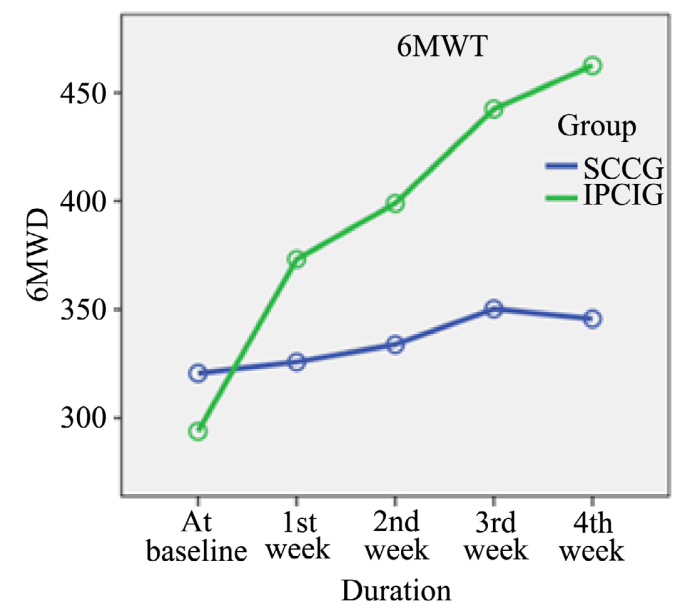

(b)

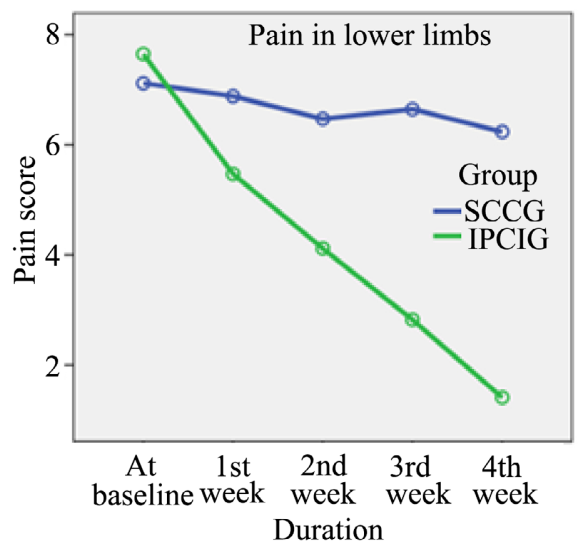

(d)

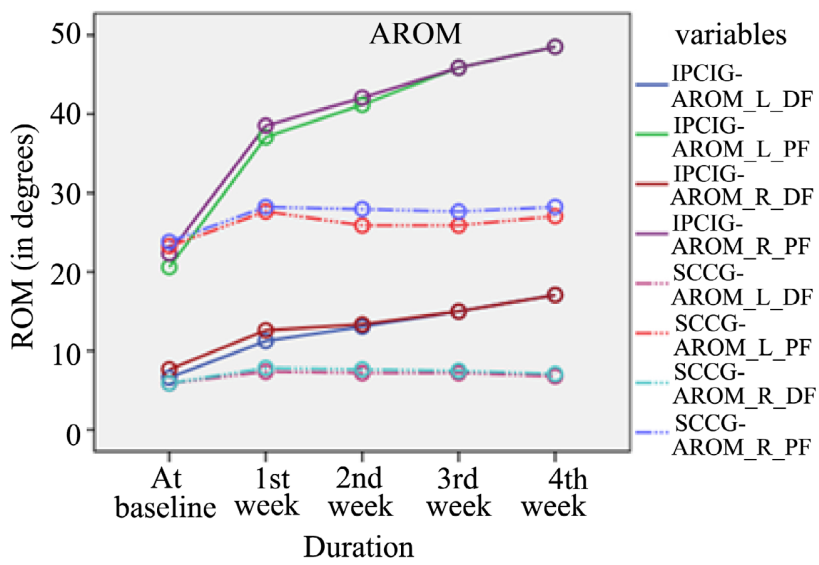

(e)

Figure 2. Comparison of mean changes of outcome measures over time between IPCIG and SCCG, IPCIG = Intermittent pneumatic compression intervention group, SCCG = Static Compression Control Group, QOL = Quality of life; $6 \mathrm{MWT}=$ Six minute walk test; $6 \mathrm{MWD}=$ Six minute walk distance; TUG = Timed up and Go Test; AROM; Ankle range of motion; ROM = Range of motion; DF = Dorsiflexion; PL; Plantar flexion; $\mathrm{L}=$ left; $\mathrm{R}=$ Right. (a): Comparison of mean changes of QOL scores over time between IPCIG and SCCG across the intervention; (b): Comparison of mean changes of 6 MWT scores over time between IPCIG and SCCG across the intervention; (c): Comparison of mean changes of TUG scores over time between IPCIG and SCCG across the intervention; (d): Comparison of mean changes of lower leg pain scores over time between IPCIG and SCCG across the intervention; (e): Comparison of mean changes of lower AROM over time between IPCIG and SCCG across the intervention. 
Table 3. Comparison of post interventional QOL outcomes between IPCIG and SCCG ${ }^{\mathrm{a}}$.

\begin{tabular}{ccccc}
\hline Variable & $\begin{array}{c}\text { Mean values } \\
\text { of IPCIG }\end{array}$ & $\begin{array}{c}\text { Mean values } \\
\text { of SCCG }\end{array}$ & $\begin{array}{c}\text { Observed } \\
\text { power }\end{array}$ & P value \\
\hline $\begin{array}{c}\text { General health } \\
\text { Physical function }\end{array}$ & $63.99(15.046)$ & $45.05(15.065)$ & 0.945 & $0.00088^{*}$ \\
$\begin{array}{c}\text { Role limitations due to } \\
\text { physical health problems }\end{array}$ & $73.24(21.933)$ & $43.24(16.950)$ & 0.991 & $0.00009^{*}$ \\
$\begin{array}{c}\text { Role limitations } \\
\text { due to emotional problems }\end{array}$ & $86.27(31.315)$ & $19.11(31.145)$ & 1.000 & $0.00000^{*}$ \\
$\begin{array}{c}\text { Social functioning } \\
\text { Bodily pain }\end{array}$ & $78.50(22.786)$ & $48.53(25.342)$ & 0.940 & $0.00099^{*}$ \\
Energy/fatigue & $75.32(16.841)$ & $40.74(25.736)$ & 0.994 & $0.00006^{*}$ \\
Emotional well being & $77.06(18.713)$ & $53.56(14.663)$ & 0.997 & $0.00028^{*}$ \\
$\quad 79.76(16.215)$ & $59.06(16.873)$ & 0.943 & $0.00093^{*}$ \\
Total QOL & $76.51(16.0412)$ & $41.05(12.898)$ & 1.000 & $0.00000^{*}$ \\
\hline
\end{tabular}

$\mathrm{QOL}=$ Quality of life; $\mathrm{N}=$ Number of participants; ${ }^{*}=$ Statistically significant difference with bonferroni correction 0.00138 ; at $95 \%$ confidence interval.

Table 4. QOL variation with time compare within the IPCIG and SCCG ${ }^{\mathrm{a}}$.

\begin{tabular}{|c|c|c|c|c|c|c|}
\hline \multirow[b]{2}{*}{ Variable } & \multicolumn{3}{|c|}{ Within IPCIG } & \multicolumn{3}{|c|}{ Within SCCG } \\
\hline & $\begin{array}{c}\text { Baseline } \\
\text { mean }(\mathrm{Sd})\end{array}$ & $\begin{array}{c}\text { Post } \\
\text { Intervention } \\
\text { mean }(\mathrm{Sd})\end{array}$ & $\begin{array}{c}P \\
\text { value }\end{array}$ & $\begin{array}{l}\text { Baseline } \\
\text { mean (Sd) }\end{array}$ & $\begin{array}{c}\text { Post } \\
\text { Intervention } \\
\text { mean }(\mathrm{Sd})\end{array}$ & $\begin{array}{c}P \\
\text { value }\end{array}$ \\
\hline $\begin{array}{l}\text { General } \\
\text { health }\end{array}$ & $29.87(18.071)$ & $63.99(15.046)$ & $0.00001^{\star}$ & $43.31(3.737)$ & $45.05(3.654)$ & 0.570 \\
\hline Physical function & $40.88(19.704)$ & $73.24(21.933)$ & $0.00000^{*}$ & $45.59(4.575)$ & $43.24(4.111)$ & 0.589 \\
\hline $\begin{array}{c}\text { Role } \\
\text { limitations } \\
\text { due to physical } \\
\text { health } \\
\text { problems }\end{array}$ & $8.82(24.908)$ & 77.94 (32.933) & $0.00000^{*}$ & $13.24(8.055)$ & $19.12(5.882)$ & 0.361 \\
\hline $\begin{array}{l}\text { Role } \\
\text { limitations } \\
\text { due to } \\
\text { emotional } \\
\text { problems }\end{array}$ & $31.37(46.354)$ & $86.27(31.315)$ & $0.001^{*}$ & $19.12(9.474)$ & $19.11(7.554)$ & 0.999 \\
\hline $\begin{array}{c}\text { Social } \\
\text { functioning }\end{array}$ & $63.24(16.812)$ & $78.50(22.786)$ & 00.038 & $57.29(5.469)$ & $48.53(6.146)$ & 0.140 \\
\hline Bodily Pain & $41.32(27.615)$ & $75.32(16.841)$ & $0.00017^{\star}$ & $44.41(8.167)$ & $40.74(6.242)$ & 0.555 \\
\hline Energy/fatigue & $50.81(15.416)$ & $77.06(18.713)$ & $0.00012^{\star}$ & $54.12(5.511)$ & $53.56(3.556)$ & 0.915 \\
\hline $\begin{array}{l}\text { Emotional } \\
\text { well being }\end{array}$ & $61.71(13.855)$ & $79.76(16.215)$ & $0.001^{*}$ & $59.29(3.034)$ & $59.06(4.092)$ & 0.956 \\
\hline QOL & $41(9.863)$ & $76.51(16.041)$ & $0.00000^{*}$ & $42.05(4.165)$ & $41.05(3.128)$ & 0.751 \\
\hline
\end{tabular}

${ }^{\mathrm{a}} \mathrm{QOL}=$ Quality of Life; $\mathrm{BL}=$ Base Line; PI $=$ Post Intervention; ${ }^{*}=$ Statistically significant difference with bonferroni correction 0.0027 ; at $95 \%$ confidence interval. 
Table 5. Comparison of secondary outcomes between IPCIG and SCCGa in different time points.

\begin{tabular}{|c|c|c|c|c|c|c|c|c|c|c|c|c|c|c|c|}
\hline \multirow{3}{*}{$\begin{array}{l}\text { Time } \\
\text { Point }\end{array}$} & \multirow{3}{*}{ Group } & \multicolumn{8}{|c|}{ Ankle Range of Motion } & \multirow{2}{*}{\multicolumn{2}{|c|}{ Pain }} & \multirow{2}{*}{\multicolumn{2}{|c|}{ TUG Test }} & \multirow{2}{*}{\multicolumn{2}{|c|}{$6 \mathrm{MWT}$}} \\
\hline & & \multicolumn{2}{|c|}{$\begin{array}{c}\text { Left side } \\
\text { Dorsi-flexion }\end{array}$} & \multicolumn{2}{|c|}{$\begin{array}{c}\text { Left side } \\
\text { Plantar flexion }\end{array}$} & \multicolumn{2}{|c|}{$\begin{array}{c}\text { Right side } \\
\text { Dorsi-flexion }\end{array}$} & \multicolumn{2}{|c|}{$\begin{array}{c}\text { Right side } \\
\text { Plantar flexion }\end{array}$} & & & & & & \\
\hline & & $\begin{array}{l}\text { Mean } \\
(\mathrm{Sd})\end{array}$ & $\begin{array}{c}\mathrm{P} \\
\text { value }\end{array}$ & $\begin{array}{l}\text { Mean } \\
(\mathrm{Sd})\end{array}$ & $\begin{array}{c}\mathrm{P} \\
\text { value }\end{array}$ & $\begin{array}{l}\text { Mean } \\
(\mathrm{Sd})\end{array}$ & $\begin{array}{c}\mathrm{P} \\
\text { value }\end{array}$ & $\begin{array}{l}\text { Mean } \\
(\mathrm{Sd})\end{array}$ & $\begin{array}{c}\mathrm{P} \\
\text { value }\end{array}$ & $\begin{array}{l}\text { Mean } \\
(\mathrm{Sd})\end{array}$ & $\begin{array}{c}\mathrm{P} \\
\text { value }\end{array}$ & $\begin{array}{l}\text { Mean } \\
(\mathrm{Sd})\end{array}$ & $\begin{array}{c}\mathrm{P} \\
\text { value }\end{array}$ & $\begin{array}{c}\text { Mean } \\
(\mathrm{Sd})\end{array}$ & $\begin{array}{c}\mathrm{P} \\
\text { value }\end{array}$ \\
\hline Week & IPCIG & $\begin{array}{c}11.24 \\
(2.488)\end{array}$ & & $\begin{array}{c}37.06 \\
(12.507)\end{array}$ & & $\begin{array}{c}12.59 \\
(3.554)\end{array}$ & & $\begin{array}{c}38.53 \\
(8.973)\end{array}$ & & $\begin{array}{c}5.47 \\
(2.267)\end{array}$ & & $\begin{array}{c}15.03 \\
(2.536)\end{array}$ & & $\begin{array}{c}373.18 \\
(73.238)\end{array}$ & \\
\hline 1 & SCCG & $\begin{array}{c}7.35 \\
(6.403)\end{array}$ & 0.026 & $\begin{array}{c}27.65 \\
(12.884)\end{array}$ & 0.038 & $\begin{array}{c}7.82 \\
(5.855)\end{array}$ & 0.007 & $\begin{array}{c}28.24 \\
(12.112)\end{array}$ & 0.008 & $\begin{array}{c}6.88 \\
(1.965)\end{array}$ & 0.061 & $\begin{array}{c}22.27 \\
(24.25)\end{array}$ & 0.230 & $\begin{array}{c}325.82 \\
(71.237)\end{array}$ & 0.065 \\
\hline & IPCIG & $\begin{array}{c}13.06 \\
(3.491)\end{array}$ & & $\begin{array}{l}41.18 \\
(8.932)\end{array}$ & & $\begin{array}{c}13.35 \\
(3.427)\end{array}$ & & $\begin{array}{c}42.06 \\
(9.852)\end{array}$ & & $\begin{array}{c}4.12 \\
(1.654)\end{array}$ & & $\begin{array}{c}11.94 \\
(2.406)\end{array}$ & & $\begin{array}{c}399.00 \\
(65 / 780)\end{array}$ & \\
\hline $\begin{array}{c}\text { Week } \\
2\end{array}$ & SCCG & $\begin{array}{c}7.18 \\
(6.366)\end{array}$ & 0.002 & $\begin{array}{c}25.88 \\
(13.019)\end{array}$ & $0.00035^{*}$ & $\begin{array}{c}7.65 \\
(5.830)\end{array}$ & 0.001 & $\begin{array}{c}27.94 \\
(11.189)\end{array}$ & $0.00046^{*}$ & $\begin{array}{c}6.47 \\
(2.154)\end{array}$ & 0.001 & $\begin{array}{c}15.36 \\
(3.331)\end{array}$ & 0.002 & $\begin{array}{l}333.82 \\
(7.700)\end{array}$ & 0.009 \\
\hline & IPCIG & $\begin{array}{c}15.00 \\
(4.677)\end{array}$ & & $\begin{array}{c}45.88 \\
(8.703)\end{array}$ & & $\begin{array}{l}15.000 \\
(4.667)\end{array}$ & & $\begin{array}{c}45.88 \\
(8.703)\end{array}$ & & $\begin{array}{c}2.82 \\
(1.074)\end{array}$ & & $\begin{array}{c}10.64 \\
(2.030)\end{array}$ & & $\begin{array}{c}442.41 \\
(67.373)\end{array}$ & \\
\hline 3 & SCCG & $\begin{array}{c}7.18 \\
(6.116)\end{array}$ & $0.00025^{*}$ & $\begin{array}{c}25.88 \\
(12.277)\end{array}$ & $0.00001^{*}$ & $\begin{array}{c}7.47 \\
(5.864)\end{array}$ & $0.00024^{\star}$ & $\begin{array}{c}27.65 \\
(10.476)\end{array}$ & $0.00000^{*}$ & $\begin{array}{c}6.65 \\
(2.120)\end{array}$ & $0.0000^{*}$ & $\begin{array}{c}14.80 \\
(3.000)\end{array}$ & $0.000042^{*}$ & $\begin{array}{c}350.29 \\
(71.249)\end{array}$ & $0.00049^{*}$ \\
\hline & IPCIG & $\begin{array}{c}17.06 \\
(5.607)\end{array}$ & & $\begin{array}{c}48.53 \\
(7.859)\end{array}$ & & $\begin{array}{c}17.06 \\
(5.607)\end{array}$ & & $\begin{array}{c}48.53 \\
(7.859)\end{array}$ & & $\begin{array}{c}1.41 \\
(.870)\end{array}$ & & $\begin{array}{c}9.43 \\
(1.093)\end{array}$ & & $\begin{array}{c}462.53 \\
(72.804)\end{array}$ & \\
\hline 4 & SCCG & $\begin{array}{c}6.76 \\
(5.847)\end{array}$ & $0.00001^{*}$ & $\begin{array}{c}27.06 \\
(11.600)\end{array}$ & $0.00000^{*}$ & $\begin{array}{c}7.06 \\
(5.607)\end{array}$ & $0.00001^{*}$ & $\begin{array}{c}28.24 \\
(9.510)\end{array}$ & $0.00000^{*}$ & $\begin{array}{c}6.24 \\
(2.016)\end{array}$ & $0.0000^{*}$ & $\begin{array}{c}14.33 \\
(3.102)\end{array}$ & $0.00000^{*}$ & $\begin{array}{c}345.71 \\
(67.849)\end{array}$ & $0.00003^{*}$ \\
\hline
\end{tabular}

aTUG Test $=$ Timed up and Go Test, 6 MWT $=$ six minute walk test, IPCIG = Intermittent Pneumatic Compression Intervention Group, SCCG $=$ Static Compression Control Group at $95 \%$ Confidence Interval, ${ }^{*}=$ Statistically significant difference with bonferroni correction of 0.00071 . aPairwise comparison was carried out only in outcome measures that shows a significant variation $(\mathrm{P} \leq 0.05)$ in mean values, within the groups with the time when analyzed using one way repeated measure ANOVA

SCCG $(\mathrm{P} \leq 0.00071)$ (Table 5, Figure 2(c)). Also results shows that improvement of $6 \mathrm{MWT}$ was continuous during the whole period of intervention in IPCIG (Table 6). Pairwise comparison of mean values of TUG over 4 weeks in IPCIG shows a significant difference $(\mathrm{P} \leq 0.00036)$ among baseline and 2nd week, 3rd week, 4th week respectively as well as between 1st week and 3rd week, 4 th week respectively (Table 7). In addition to that positive mean difference shows that mean value of TUG is decreasing over time significantly within IPCIG (Table 7).

Pairwise comparison between groups at each time point show that there is a significant improvement in lower leg pain of IPCIG at 3rd and 4th week comparatively to SCCG $(\mathrm{P} \leq 0.00071)$ (Table 5, Figure $2(\mathrm{~d})$ ). Pairwise comparison of mean values of lower leg pain over 4 weeks within IPCIG shows a significant difference $(\mathrm{P} \leq 0.0036)$ among all weekly outcome except between week 1 and 2 , week 2 and 3, week 3 and 4 (Table 7). In addition, positive mean difference shows that mean value of pain is decreasing over time significantly within IPCIG (Table 7). The mean difference of lower leg pain within IPCIG between baseline and week 1 was reduced significantly by $2.176(\mathrm{P} \leq 0.00020)$ and it shows that even 1 week of initial application of IPC is effective in reduction of lower leg 
Table 6. Mean values of secondary outcomes within IPCIG and SCCG in different time points ${ }^{\mathrm{a}}$.

\begin{tabular}{|c|c|c|c|c|c|c|c|c|}
\hline \multirow[b]{2}{*}{ Group } & \multirow[b]{2}{*}{$\begin{array}{l}\text { Time } \\
\text { point }\end{array}$} & \multicolumn{7}{|c|}{ Variables } \\
\hline & & $\begin{array}{c}\text { Left side } \\
\text { Dorsi-Flexion } \\
\text { Mean (Sd) }\end{array}$ & $\begin{array}{l}\text { Left side } \\
\text { Plantar } \\
\text { flexion } \\
\text { Mean (Sd) }\end{array}$ & $\begin{array}{c}\text { Right side } \\
\text { Dorsi-flexion } \\
\text { Mean (Sd) }\end{array}$ & $\begin{array}{l}\text { Right side } \\
\text { Plantar } \\
\text { flexion } \\
\text { Mean (Sd) }\end{array}$ & $\begin{array}{c}\text { Pain } \\
\text { Mean (Sd) }\end{array}$ & $\begin{array}{l}\text { TUG Test } \\
\text { Mean (Sd) }\end{array}$ & $\begin{array}{c}6 \text { MWT } \\
\text { Mean (Sd) }\end{array}$ \\
\hline \multirow{5}{*}{ IPCIG } & Baseline & $6.59(3.411)$ & $20.59(11.576)$ & $7.65(5.623)$ & 22.35 (11.197) & $7.65(1.539)$ & $17.65(3.263)$ & $293.82(48.332)$ \\
\hline & $1^{\text {st }}$ week & $11.24(2.488)$ & $37.06(12.507)$ & $12.59(3.554)$ & 38.53 (8.973) & $5.47(2.267)$ & $15.03(2.535)$ & $373.18(73.238)$ \\
\hline & $2^{\text {nd }}$ week & $13.06(3.491)$ & $41.18(8.932)$ & $13.35(3.427)$ & $42.06(9.852)$ & $4.12(1.654)$ & $11.93(2.406)$ & $399.00(65.780)$ \\
\hline & $3^{\text {rd }}$ week & $15.00(4.677)$ & $45.88(8.703)$ & $15.00(4.677)$ & $45.88(8.703)$ & $2.82(1.074)$ & $10.64(2.030)$ & $442.41(7.373)$ \\
\hline & $4^{\text {th }}$ week & $17.06(5.607)$ & $48.53(7.859)$ & $17.06(5.607)$ & $48.53(7.859)$ & $1.41(.870)$ & $9.43(1.093)$ & $462.53(72.804)$ \\
\hline \multirow{5}{*}{ SCCG } & Baseline & $5.88(5.372)$ & $23.24(11.172)$ & $5.88(5.372)$ & $23.82(10.973)$ & $7.12(1.965)$ & $16.79(3.323)$ & $320.59(83.120)$ \\
\hline & $1^{\text {st }}$ week & $7.35(6.403)$ & $27.65(12.884)$ & $7.82(5.855)$ & $28.24(12.112)$ & $6.88(1.965)$ & $22.26(24.254)$ & $325.82(71.237)$ \\
\hline & $2^{\text {nd }}$ week & $7.18(6.366)$ & 25.88 (13.019) & $7.65(5.830)$ & 27.94 (11.189) & $6.47(2.154)$ & $15.36(3.331)$ & $333.82(70.700)$ \\
\hline & $3^{\text {rd }}$ week & $7.18(6.116)$ & $25.88(12.277)$ & $7.47(5.864)$ & $27.65(10.476)$ & $6.65(2.120)$ & $14.80(3.000)$ & $350.29(71.249)$ \\
\hline & $4^{\text {th }}$ week & $6.76(5.847)$ & $27.06(11.600)$ & $7.06(5.607)$ & $28.24(9.510)$ & $6.24(2.016)$ & $14.32(3.102)$ & $345.71(67.849)$ \\
\hline
\end{tabular}

aTUG Test = Timed up and Go Test; 6 MWT = six minute walk test; IPCIG = Intermittent Pneumatic Compression Intervention Group; SCCG = Static Compression Control Group.

Table 7. Pairwise comparison for lower leg pain, TUG, 6 MWT and Ankle ROM with time within the IPCIG.

\begin{tabular}{|c|c|c|c|c|c|c|c|c|c|c|c|c|c|c|c|}
\hline \multirow{2}{*}{\multicolumn{2}{|c|}{ Time Point }} & \multicolumn{8}{|c|}{ Ankle Range of Motion } & \multirow{2}{*}{\multicolumn{2}{|c|}{ Pain }} & \multirow{2}{*}{\multicolumn{2}{|c|}{ TUG Test }} & \multirow{2}{*}{\multicolumn{2}{|c|}{$6 \mathrm{MWT}$}} \\
\hline & & \multicolumn{2}{|c|}{$\begin{array}{c}\text { Left side } \\
\text { Dorsi-flexion }\end{array}$} & \multicolumn{2}{|c|}{$\begin{array}{c}\text { Left side } \\
\text { Plantar flexion }\end{array}$} & \multicolumn{2}{|c|}{$\begin{array}{c}\text { Right side } \\
\text { Dorsi-flexion }\end{array}$} & \multicolumn{2}{|c|}{$\begin{array}{c}\text { Right side } \\
\text { Plantar flexion }\end{array}$} & & & & & & \\
\hline $\begin{array}{l}\text { (I) } \\
\text { time }\end{array}$ & $\begin{array}{l}(\mathrm{J}) \\
\text { time }\end{array}$ & $\begin{array}{c}\text { Mean } \\
\text { Difference } \\
\text { within } \\
\text { IPCIG } \\
(\mathrm{I}-\mathrm{J})\end{array}$ & $\begin{array}{c}\mathrm{P} \\
\text { value }\end{array}$ & $\begin{array}{c}\text { Mean } \\
\text { Difference } \\
\text { within } \\
\text { IPCIG } \\
(\mathrm{I}-\mathrm{J})\end{array}$ & $\begin{array}{c}\mathrm{P} \\
\text { value }\end{array}$ & $\begin{array}{c}\text { Mean } \\
\text { Difference } \\
\text { within } \\
\text { IPCIG } \\
(\mathrm{I}-\mathrm{J})\end{array}$ & $\begin{array}{c}\mathrm{P} \\
\text { value }\end{array}$ & $\begin{array}{c}\text { Mean } \\
\text { Difference } \\
\text { within } \\
\text { IPCIG } \\
(\mathrm{I}-\mathrm{J})\end{array}$ & $\begin{array}{c}\mathrm{P} \\
\text { value }\end{array}$ & $\begin{array}{c}\text { Mean } \\
\text { Difference } \\
\text { within } \\
\text { IPCIG } \\
(\mathrm{I}-\mathrm{J})\end{array}$ & $\begin{array}{c}\mathrm{P} \\
\text { value }\end{array}$ & $\begin{array}{c}\text { Mean } \\
\text { Difference } \\
\text { within } \\
\text { IPCIG } \\
(\mathrm{I}-\mathrm{J})\end{array}$ & $\begin{array}{c}\mathrm{P} \\
\text { value }\end{array}$ & $\begin{array}{c}\text { Mean } \\
\text { Difference } \\
\text { within } \\
\text { IPCIG } \\
(\mathrm{I}-\mathrm{J})\end{array}$ & $\begin{array}{c}\mathrm{P} \\
\text { value }\end{array}$ \\
\hline \multirow{4}{*}{$\begin{array}{l}\text { Base } \\
\text { Line }\end{array}$} & Week 1 & -4.647 & 0.004 & -16.471 & $0.00034^{*}$ & -4.941 & 0.001 & -16.176 & 0.001 & 2.176 & $0.00020^{*}$ & 2.624 & 0.003 & -79.353 & $0.00013^{*}$ \\
\hline & Week 2 & -6.471 & 0.003 & -20.588 & $0.00015^{*}$ & -5.706 & 0.017 & -19.706 & 0.001 & 3.529 & $0.00000^{*}$ & 5.716 & $0.00009^{*}$ & -105.176 & $0.00000^{*}$ \\
\hline & Week 3 & -8.412 & 0.001 & -25.294 & $0.00001^{*}$ & -7.353 & 0.040 & -23.529 & $0.00006^{*}$ & 4.824 & $0.00000^{*}$ & 7.015 & $0.00000^{*}$ & -148.588 & $0.00000^{*}$ \\
\hline & Week 4 & -10.471 & $0.00012^{*}$ & -27.941 & $0.00000^{*}$ & -9.412 & 0.004 & -26.176 & $0.00000^{*}$ & 6.235 & $0.00000^{*}$ & 8.222 & $0.00000^{*}$ & -168.706 & $0.00000^{*}$ \\
\hline \multirow{3}{*}{$\begin{array}{c}\text { Week } \\
1\end{array}$} & Week 2 & -1.824 & 1.000 & -4.118 & 0.999 & -.765 & 1.000 & -3.529 & 1.000 & 1.353 & 0.053 & 3.092 & 0.00038 & -25.824 & 0.004 \\
\hline & Week 3 & -3.765 & 0.119 & -8.824 & 0.082 & -2.412 & 1.000 & -7.353 & 0.088 & 2.647 & $0.00013^{*}$ & 4.391 & $0.00001^{*}$ & -69.235 & 0.002 \\
\hline & Week 4 & -5.824 & 0.007 & -11.471 & 0.00049 & -4.471 & 0.221 & -10.000 & $0.00003^{*}$ & 4.059 & $0.00002^{*}$ & 5.598 & $0.00000^{*}$ & -89.353 & 0.00044 \\
\hline \multirow{2}{*}{$\begin{array}{l}\text { Week } \\
2\end{array}$} & Week 3 & -1.941 & 0.057 & -4.706 & 0.051 & -1.647 & 0.105 & -3.824 & 0.183 & 1.294 & 0.003 & 1.299 & 0.007 & -43.412 & 0.004 \\
\hline & Week 4 & -4.000 & 0.133 & -7.353 & 0.052 & -3.706 & 0.169 & -6.471 & 0.210 & 2.706 & $0.00012^{*}$ & 2.506 & 0.005 & -63.529 & 0.00041 \\
\hline $\begin{array}{c}\text { Week } \\
3\end{array}$ & Week 4 & -2.059 & 1.000 & -2.647 & 1.000 & -2.059 & 1.000 & -2.647 & 1.000 & 1.412 & 0.001 & -1.207 & 0.200 & -20.118 & $0.00001^{*}$ \\
\hline
\end{tabular}

aTUG Test $=$ Timed up and Go Test, 6 MWT $=$ six minute walk test, IPCIG = Intermittent Pneumatic Compression Intervention Group, SCCG $=$ Static Compression Control Group at $95 \%$ Confidence Interval, ${ }^{*}=$ Statistically significant difference with bonferroni correction $0.00036 .{ }^{\text {aPairwise comparison }}$ was carried out only in outcome measures that show a significant variation $(\mathrm{P} \leq 0.05)$ in mean values, within the groups with the time when analyzed using one way repeated measure ANOVA. 
pain. Also results shows that amount of lower leg pain reduction were consistent and continuous during the whole period of intervention in IPCIG (Table 6). The mean difference of the lower leg pain between baseline and post intervention in IPCIG was $6.235(\mathrm{P} \leq 0.00000)$ and this shows that the overall pain reduction of four week intervention is noteworthy.

Pairwise comparison between groups at each time point show that there is a significant improvement in left and right ankle dorsiflexion and plantarflexion ROM of IPCIG at 3rd and 4th week comparatively to SCCG and plantar flexion of right and left ankle have significant improvement even at 2nd week in IPCIG compared to SSCG $(P \leq 0.00071)$ (Table 5, Figure 2(e)). Pairwise comparison of mean values of ROM of left dorsiflexion shows a significant difference between baseline and 4th week and plantarflexion shows a significant difference between baseline and 1st week, 2nd week, 3rd week and 4th week respectively ( $\mathrm{P} \leq$ 0.00036). Pairwise comparison of mean values of ROM of right dorsiflexion shows no significant difference between any of the weeks and plantarflexion shows a significant difference between baseline and 3rd week and 4th week respectively as well as between 1 st week and 4 th week $(\mathrm{P} \leq 0.00036)$. In addition, negative mean differences shows that mean values of ROM are increasing significantly over time within IPCIG (Table 7).

The risk difference and number needed to treat was calculated for the changes of total QOL variable over time among the IPCIG and SCCG. 80\% improvement of QOL at the end was considered as the cutoff for significant improvement of QOL. The risk difference was calculated and findings shows that the chance/risk of a state of " $80 \%$ improved QOL" is $(0.529 \times 100 \%)=53 \%$ higher after 4 weeks application of IPC than 4 weeks application of static compression. In addition to that, findings shows one patient will be improved $80 \%$ of QOL for every two patients who are treated with the IPC based on the NNT value (Appendix 2).

\section{Discussion}

To the best of our knowledge, this study is the first to document the efficacy of IPC in enhancing the functional level and QOL of community-dwelling older people with walking difficulties. We found that there were statistically significant differences between the groups in QOL (Table 3), AROM, lower leg pain, 6 MWT, and TUG test (Table 5) in favor of the IPCIG compared with the SCCG.

We expected that the IPCIG would be favored across outcomes, as per the evidence of previous studies describing the related effects of the IPC and the interventions similar to the interventions delivered by the IPC [29] [30] [31] [43]-[55]. Regarding the outcome of lower leg pain, studies have shown that massage is useful in reducing pain [29] [30] [31]. The potential massage effect of IPC may have caused the reduction of pain in the IPCIG. Furthermore, consistent and continuous reduction of lower leg pain during the whole period of intervention in the IPCIG (Tables 5-7) shows the usefulness of the continuous use of IPC.

The outcome of TUG test, which measured functional mobility, showed that 
even after 1 week, the initial application of IPC is effective in improving functional mobility (Table 7). In addition, the results show that there is a significant increase in functional mobility over time within the IPCIG (Table 6 and Table 7). Functional mobility is mainly based on the dynamic balance and stability of an individual. It has been shown that massage applied to the calf is a useful method to improve the balance of older adults who have diminished balancing abilities due to problems with their plantarflexion torque [43]. It has also been suggested that the benefits of massage may help enhance dynamic balance [44]. The possible massage effect of IPC caused an improvement in the dynamic balance and, hence, the functional mobility of the participants in the intervention group. Continuous muscle contraction of the gastrocnemius muscle to generate sufficient muscle strength is important for maintaining stability during walking and exercise [45] [46]. The possible effect of IPC to improve prompt muscle activation ability of the gastrocnemius muscle will have a positive effect on maintaining stability during walking and exercises.

There was a significant increase in walking capacity over time within the IPCIG ( $\mathrm{P} \leq 0.0005)$. Intermittent pneumatic compression improves the circulation to the muscles in the lower leg and foot, enhancing the delivery and extraction of oxygen to the muscles (aerobic capacity), necessary to sustain the repeated pattern of muscle activation during walking, and therefore improving the walking capacity in participants. Studies have shown the value of enhancing aerobic capacity to provide the energy needed to sustain the muscle activity of older adults for walking and reduce restriction of walking activity in prolonged walking conditions [47].

The improvement in the AROM in the IPCIG (Table 7) may be due to a reduction in swelling of the lower legs, which occurs as a result of IPC. Furthermore, the possible stretching effect of IPC on the lower leg muscles may have contributed to the increase in the ROM of the ankle joints. Studies have shown that massage of the calf muscle improves ankle joint flexibility [43]. The possible massage effect of the IPC has improved ankle joint flexibility and hence ROM. Several studies have shown that one of the deficit characteristics of age-related walking problems that contribute to inefficient gait is decreased ankle plantarflexion [48] [49] [50] [51] [52]. In our study, the AROM in the participants of the intervention group was improved. Therefore, it is evident that the application of IPC has a positive effect on improving walking capacity.

Regarding the main outcome of QOL and the subscales of physical function, role limitations due to physical health, role limitations due to emotional problems, social functioning, and emotional well-being at 4 weeks, the IPCIG showed a more significant improvement compared to the SCCG (Table 3). This significant improvement in the subscales, as well as QOL, which represent participation, can be described as having an association with the improvement of targeted body structure/function (lower leg pain and AROM) and activities (functional mobility and walking capacity) of the participants of the IPCIG. Several studies have demonstrated that mobility is a key determinant of QOL [53] [54] [55]. 
These studies prove our study results of improved functional mobility and walking capacity with improved QOL.

\section{Limitations and Future Research}

This study has several limitations. The sample size of this study was small. We contacted 286 individuals through recruitment strategies. However, only 64 participants participated in the eligibility screening, and only 34 were eligible. It is unknown whether the intervention dosage was optimal. The number of intervention sessions, the duration of each intervention session, and the intervention frequency, intensity, and compression pattern were meant to represent an intervention dosage that would be tolerable for the target study population. This dosage was based on clinical judgment in the absence of experimental evidence related to the optimal intervention dosage. Additionally, there were no plans to test the retention of the effects of the intervention. This limitation resulted in the unavailability of an assessment of the influence of the intervention approach on retention. Therefore, investigating the retention of the effects of IPC on QOL, walking capacity and functional mobility is suggested. Further studies are suggested to determine the effectiveness of the different IPC patterns in improving the QOL, functional mobility, and walking capacity of the older population.

\section{Conclusion}

The IPC was effective in improving QOL, reducing lower leg pain, improving the AROM (dorsiflexion and plantarflexion), and improving walking capacity and functional mobility. In addition, IPC can be identified as a user-friendly, pragmatic, and simple intervention to be used by community-dwelling older adults. Additional studies are needed to determine the optimal dosage and retention of the effects of the intervention.

\section{Author Contribution}

Dr. Weerasinghe, Dr. Karunaratne and Mr. Thunpaththu provided concept/idea/ research design and writing. Dr. Weerasinghe, Mr. Thunpaththu, Ms. Weerasinghe and Mr. Weerasinghe provided data collection. Dr. Weerasinghe, Mrs. Walpola and Ms. Weerasinghe provided the project management, fund procurement and facilities/equipment. Dr. Weerasinghe and Ms. Weerasinghe provided the data analysis. Dr. Weerasinghe and Mr. Thunpaththu and Mrs. Dissanayake provided the consultation including a review of the manuscript.

\section{Acknowledgements}

The authors acknowledge MAS Holdings for funding the study. The authors acknowledge the Department of Research Development of the Physio Life Care, Sri Lanka, for providing the Tamil version of the SF-36 questionnaire and the Institute for Research and Development for providing the Sinhala version of the SF-36 questionnaire. The authors acknowledge Dr. Thusitha Wijemanna (MP) 
for her advice and Dr. Ranjith Fernando for his medical evaluation of the participants. The authors also acknowledge Ms. H.G.P.N. Chandrasiri, Mr. W.M.S.C. Weerasinghe, and Mr. H.M.N. Bandara for their administrative assistance. The authors acknowledge the people who participated in the trial.

\section{Conflicts of Interest}

The authors declare no conflicts of interest regarding the publication of this paper.

\section{References}

[1] Ferrucci, L., Baninelli, S., Benvenuti, E., et al. (2000) Subsystems Contributing to the Decline in Ability to Walk: Bridging the Gap between Epidemiology and Geriatric Practice in the InCHIANTI Study. Journal of the American Geriatrics Society, 48, 1618-1625. https://doi.org/10.1111/j.1532-5415.2000.tb03873.x

[2] Cesari, M., Kritchevsky, S., Bauer, D.C., et al. (2005) Prognostic Value of Usual Gait Speed in Well-Functioning Older People-Results from the Health, Aging and Body Composition Study. Journal of the American Geriatrics Society, 53, 1675-1680. https://doi.org/10.1111/j.1532-5415.2005.53501.x

[3] Guralnik, J.M., Ferrucci, L., Pieper, C., et al. (2000) Lower Extremity Function and Subsequent Disability: Consistency across Studies, Predictive Models, and Value of Gait Speed Alone Compared with the Short Physical Performance Battery. The Journals of Gerontology: Series A, 55, M221-M231.

https://doi.org/10.1093/gerona/55.4.M221

[4] Guralnik, J.M., Simonsick, E.M., Ferrucci, L., et al. (1994) A Short Physical Performance Battery Assessing Lower Extremity Function: Association with Self-Reported Disability and Prediction of Mortality and Nursing Home Admission. Journal of Gerontology, 49, M85-M94. https://doi.org/10.1093/geronj/49.2.M85

[5] Guralnik, J.M., Ferrucci, L., Simonsick, E.M., Salive, M.E. and Wallace, R.B. (1995) Lower Extremity Function in Persons over the Age of 70 Years as a Predictor of Subsequent Disability. The New England Journal of Medicine, 332, 556-561. https://doi.org/10.1056/NEJM199503023320902

[6] Studenski, S., Perera, S., Patel, K., et al. (2011) Gait Speed and Survival in Older Adults. JAMA, 305, 50-58. https://doi.org/10.1001/jama.2010.1923

[7] Mahlknecht, P., Kiechl, S., Bloem, B.R., et al. (2013) Prevalence and Burden of Gait Disorders in Elderly Men and Women Aged 60-97 Years: A Population-Based Study. PLoS ONE, 8, e69627. https://doi.org/10.1371/journal.pone.0069627

[8] World Health Organization (2015) World Report on Ageing and Health.

[9] Arem, H., Moore, S.C., Patel, A., et al. (2015) Leisure Time Physical Activity and Mortality: A Detailed Pooled Analysis of the Dose-Response Relationship. JAMA Internal Medicine, 175, 959-967. https://doi.org/10.1001/jamainternmed.2015.0533

[10] Paterson, D.H. and Warburton, D.E. (2010) Physical Activity and Functional Limitations in Older Adults: A Systematic Review Related to Canada's Physical Activity Guidelines. International Journal of Behavioral Nutrition and Physical Activity, 7, Article No. 38. https://doi.org/10.1186/1479-5868-7-38

[11] Tak, E., Kuiper, R., Chorus, A. and Hopman-Rock, M. (2013) Prevention of Onset and Progression of Basic ADL Disability by Physical Activity in Community Dwelling Older Adults: A Meta-Analysis. Ageing Research Reviews, 12, 329-338. 
https://doi.org/10.1016/j.arr.2012.10.001

[12] Jak, A.J. (2012) The Impact of Physical and Mental Activity on Cognitive Aging. In: Pardon, M.C. and Bondi, M., Eds., Behavioral Neurobiology of Aging. Current Topics in Behavioral Neurosciences, Springer, Berlin, 273-291. https://doi.org/10.1007/7854_2011_141

[13] Blondell, S.J., Hammersley-Mather, R. and Veerman, J.L. (2014) Does Physical Activity Prevent Cognitive Decline and Dementia?: A Systematic Review and Meta-Analysis of Longitudinal Studies. BMC Public Health, 14, Article No. 510. https://doi.org/10.1186/1471-2458-14-510

[14] Norton, S., Matthews, F.E., Barnes, D.E., Yaffe, K. and Brayne, C. (2014) Potential for Primary Prevention of Alzheimer's Disease: An Analysis of Population-Based Data. The Lancet Neurology, 13, 788-794. https://doi.org/10.1016/S1474-4422(14)70136-X

[15] Diep, L., Kwagyan, J., Kurantsin-Mills. J., Weir, R. and Jayam-Trouth, A. (2010) Association of Physical Activity Level and Stroke Outcomes in Men and Women: A Meta-Analysis. Journal of Women's Health, 19, 1815-1822.

https://doi.org/10.1089/jwh.2009.1708

[16] Hortobagyi, T., Lesinski, M., Gabler, M., VanSwearingen, J.M., Malatesta, D. and Granacher, U. (2015) Effects of Three Types of Exercise Interventions on Healthy old Adults' Gait Speed: A Systematic Review and Meta-Analysis. Sports Medicine, 45, 1627-1643. https://doi.org/10.1007/s40279-015-0371-2

[17] Judge, J.O., Underwood, M. and Gennosa, T. (1993) Exercise to Improve Gait Velocity in Older Persons. Archives of Physical Medicine and Rehabilitation, 74, 400-406.

[18] Brown, M. and Holloszy, J.O. (1991) Effects of a Low Intensity Exercise Program on Selected Physical Performance Characteristics of 60- to 71-Year Olds. Aging Clinical and Experimental Research, 3, 129-139. https://doi.org/10.1007/BF03323989

[19] Fiatarone, M.A., O’Neill, E.F., Ryan, N.D., et al. (1994) Exercise Training and Nutritional Supplementation for Physical Frailty in Very Elderly People. The New England Journal of Medicine, 330, 1769-1775. https://doi.org/10.1056/NEJM199406233302501

[20] Pahor, M., Blair, S.N., et al. (2006) Effects of a Physical Activity Intervention on Measures of Physical Performance: Results of the Lifestyle Interventions and Independence for Elders Pilot (LIFE-P) Study. The Journals of Gerontology. Series A, 61, 1157-1165. https://doi.org/10.1093/gerona/61.11.1157

[21] Sauvage, L.R., Myklebust, B.M., Crow-Pan, J., et al. (1992) A Clinical Trial of Strengthening and Aerobic Exercise to Improve Gait and Balance in Elderly Male Nursing Home Residents. American Journal of Physical Medicine \& Rehabilitation, 71, 333-342. https://doi.org/10.1097/00002060-199212000-00005

[22] Topp, R., Mikesky, A., Wigglesworth, J., Holt, W. and Edwards, J.E. (1993) The Effect of a 12-Week Dynamic Resistance Strength Training Program on Gait Velocity and Balance of Older Adults. The Gerontologist, 33, 501-506.

https://doi.org/10.1093/geront/33.4.501

[23] Bean, J.F., Herman, S., Kiely, D.K., et al. (2004) Increased Velocity Exercise Specific to Task Training: A Pilot Study Exploring Effects on Leg Power, Balance, and Mobility in Community Dwelling Older Women. Journal of the American Geriatrics Society, 52, 799-804. https://doi.org/10.1111/j.1532-5415.2004.52222.x

[24] Buchner, D.M., Cress, M.E., de Lateur, B.J., et al. (1997) A Comparison of the Effects of Three Types of Endurance Training on Balance and Other Fall Risk Factors 
in Older Adults. Aging Clinical and Experimental Research, 9, 112-119. https://doi.org/10.1007/BF03340136

[25] Buchner, D.M., Cress, M.E., de Lateur, B.J., Esselman, P.C., et al. (1997) The Effects of Strength and Endurance Training on Gait, Balance, Fall Risk, and Health Services Use in Community-Living Older Adults. The Journals of Gerontology: Series A, 52, M218-M224. https://doi.org/10.1093/gerona/52A.4.M218

[26] Helbostad, J.L., Sletvold, O. and Moe-Nilssen, R. (2004) Home Training with and without Additional Group Training in Physically Frail Older People Living at Home: Effect on Health-Related Quality of Life and Ambulation. Clinical Rehabilitation, 18, 498-508. https://doi.org/10.1191/0269215504cr761oa

[27] Wolf, S.L., O'Grady, M., Easley, K.A., Guo, Y., Kressig, R.W. and Kutner, M. (2006) The Influence of Intense Tai Chi Training on Physical Performance and Hemodynamic Outcomes in Transitionally Frail, Older Adults. The Journals of Gerontology: Series A, 61, 184-189. https://doi.org/10.1093/gerona/61.2.184

[28] Manini, T., Marko, M., VanArnam, T., et al. (2007) Efficacy of Resistance and Task-Specific Exercise in Older Adults Who Modify Tasks of Everyday Life. The Journals of Gerontology: Series A, 62, 616-623. https://doi.org/10.1093/gerona/62.6.616

[29] Elkady, R., Tawfick, W., Hynes, N., Kavanagh, E. P., Jordan, F. and Sultan, S. (2018) Intermittent Pneumatic Compression for Critical Limb Ischaemia. The Cochrane Database of Systematic Reviews, 2018, Article No. CD013072. https://doi.org/10.1002/14651858.CD013072,

[30] Field, T., Diego, M., Cullen, C., Hernandez-Reif, M., Sunshine, W. and Douglas, S. (2002) Fibromyalgia Pain and Substance P Decrease and Sleep Improves after Massage Therapy. Journal of Clinical Rheumatology, 8, 72-76. https://doi.org/10.1097/00124743-200204000-00002

[31] Hernandez-Reif, M., Field, T., Krasnegor, J. and Theakston, H. (2001) Lower Back pain is Reduced and Range of Motion Increased after Massage Therapy. International Journal of Neuroscience, 106, 131-145. https://doi.org/10.3109/00207450109149744

[32] Badger, C.M.A., Peacock, J.L. and Mortimer, P.S. (2000) A Randomized, Controlled, Parallel-Group Clinical Trial Comparing Multilayer Bandaging Followed by Hosiery Versus Hosiery Alone in the Treatment of Patients with Lymphedema of the Limb. Cancer, 88, 2832-2837. https://doi.org/10.1002/1097-0142(20000615)88:12<2832::AID-CNCR24>3.0.CO;2$\underline{\mathrm{U}}$

[33] Ramaswami, G., D’Ayala, M., Hollier, L.H., Deutsch, R. and McElhinney, A.J. (2005) Rapid Foot and Calf Compression Increases Walking Distance in Patients with Intermittent Claudication: Results of a Randomized Study. Journal of Vascular Surgery, 41, 794-801. https://doi.org/10.1016/j.jvs.2005.01.045

[34] Partsch, B. and Partsch, H. (2005) Calf Compression Pressure Required to Achieve Venous Closure from Supine to Standing Positions. Journal of Vascular Surgery, 42, 734-738. https://doi.org/10.1016/j.jvs.2005.06.030

[35] World Health Organization (2002) Towards a Common Language for Functioning, Disability and Health: ICF.

[36] Walters, S., Munro, J. and Brazier, J. (2001) Using the SF-36 with Older Adults: A Cross-Sectional Community-Based Survey. Age and Ageing, 30, 337-343. https://doi.org/10.1093/ageing/30.4.337

[37] Harada, N.D., Chiu, V. and Stewart, A.L. (1999) Mobility-Related Function in Older 
Adults: Assessment with a 6-Minute Walk Test. Archives of Physical Medicine and Rehabilitation, 80, 837-841. https://doi.org/10.1016/S0003-9993(99)90236-8

[38] Perera, S., Mody, S., Woodman, R.C. and Studenski, S.A. (2006) Meaningful Change and Responsiveness in Common Physical Performance Measures in Older Adults. Journal of the American Geriatrics Society, 54, 743-749.

https://doi.org/10.1111/j.1532-5415.2006.00701.x

[39] Steffen, T.M., Hacker, T.A. and Mollinger, L. (2002) Age- and Gender-Related Test Performance in Community-Dwelling Elderly People: Six-Minute Walk Test, Berg Balance Scale, Timed up \& Go Test, and Gait Speeds. Physical Therapy, 82, 128-137. https://doi.org/10.1093/ptj/82.2.128

[40] Donoghue, O.A., Savva, G.M., Börsch-Supan, A. and Kenny, R.A. (2019) Reliability, Measurement Error and Minimum Detectable Change in Mobility Measures: A Cohort Study of Community-Dwelling Adults Aged 50 Years and over in Ireland. BMJ Open, 9, pe030475. https://doi.org/10.1136/bmjopen-2019-030475

[41] Herr, K. and Mobily, P. (1993) Comparison of Selected Pain Assessment Tools for Use with the Elderly. Applied Nursing Research, 6, 39-46.

https://doi.org/10.1016/S0897-1897(05)80041-2

[42] Herr, K.A. and Garand, L. (2001) Assessment and measurement of pain in older adults. Clinics in Geriatric Medicine, 17, 457-478. https://doi.org/10.1016/S0749-0690(05)70080-X

[43] Park, J., Shim, J., Kim, S., et al. (2017) Application of Massage for Ankle Joint Flexibility and Balance. Journal of Physical Therapy Science, 29, 789-792.

https://doi.org/10.1589/jpts.29.789

[44] Kaplan, A.S., Uğurlu, S.B., Pamuk, Ö., et al. (2014) Effect of Sport Massage on Pressure Pain Threshold and Tolerance in Athletes under Eccentric Exercise. International Journal of Science Culture and Sport, 2, 136-146. https://doi.org/10.14486/IJSCS185

[45] Youm, C.H. and Kim, T.H. (2012) Effects of Induced Fatigue of Ankle Joint Muscle on the Capability and Recovery of Postural Control during Single-Leg Stance. Korean Journal of Sport Biomechanics, 22, 219-228. https://doi.org/10.5103/KJSB.2012.22.2.219

[46] Lee, J.Y., Park, J.S., Lee, D.H., et al. (2012) Effect of the Trunk Muscle Stabilization Training on Balance for Chronic Stroke Patients. Journal of the Korea Academia-Industrial Cooperation Society, 13, 1212-1219. https://doi.org/10.5762/KAIS.2012.13.3.1212

[47] Gault, M. and Willems, M. (2014) Walking and Aerobic Capacity in Old Adults after Concentric and Eccentric Endurance Exercise at Self-Selected Intensities. Health, 6, 654-663. https://doi.org/10.4236/health.2014.68085

[48] McGibbon, C.A. and Krebs, D. (2001) Age-Related Changes in Lower Trunk Coordination and Energy Transfer during Gait. Journal of Neurophysiology, 85, 1923-1931. https://doi.org/10.1152/jn.2001.85.5.1923

[49] Kerrigan, D., Todd, M.K., Della Croce, U., Lipsitz, L.A. and Collins, J.J. (1998) Biomechanical Gait Alterations Independent of Speed in the Healthy Elderly: Evidence for Specific Limiting Impairments. Archives of Physical Medicine and Rehabilitation, 79, 317-322. https://doi.org/10.1016/S0003-9993(98)90013-2

[50] Lewis, G.N., Byblow. W.D. and Walt, S.E. (2000) Stride Length Regulation in Parkinson's Disease: The Use of Extrinsic, Visual Cues. Brain, 123, 2077-2090. https://doi.org/10.1093/brain/123.10.2077

[51] McGibbon, C.A. (2003) Toward a Better Understanding of Gait Changes with Age 
and Disablement: Neuromuscular Adaption. Exercise and Sport Sciences Reviews, 31, 102-108. https://doi.org/10.1097/00003677-200304000-00009

[52] DeVita, P. and Hortobagyi, T. (2000) Age Causes a Redistribution of Joint Torques and Powers during Gait. Journal of Applied Physiology, 88, 1804-1811.

https://doi.org/10.1152/jappl.2000.88.5.1804

[53] Fagerström, C. and Borglin, G. (2010) Mobility, Functional Ability and Health-Related Quality of Life among People of 60 Years or Older. Aging Clinical and Experimental Research, 22, 387-394. https://doi.org/10.1007/BF03324941

[54] Sartor-Glittenberg, C., Lehmann, S., Okada, M., Rosen, D., Brewer, K. and Bay, R.C. (2014) Variables Explaining Health Related Quality of Life in Community-Dwelling Older Adults. Journal of Geriatric Physical Therapy, 37, 83-91.

https://doi.org/10.1519/JPT.0b013e3182a4791b

[55] Trombetti, A., Reid, K.F., Hars, M., et al. (2016) Age-Associated Declines in Muscle Mass, Strength, Power, and Physical Performance: Impact on Fear of Falling and Quality of Life. Osteoporosis International, 27, 463-471.

https://doi.org/10.1007/s00198-015-3236-5 


\section{Appendix 1}

Application of intermittent pneumatic compression (IPC) using an IPC device and static compression using a static compression garment

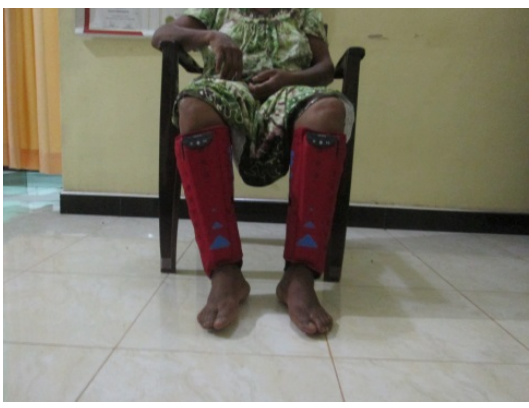

(a)

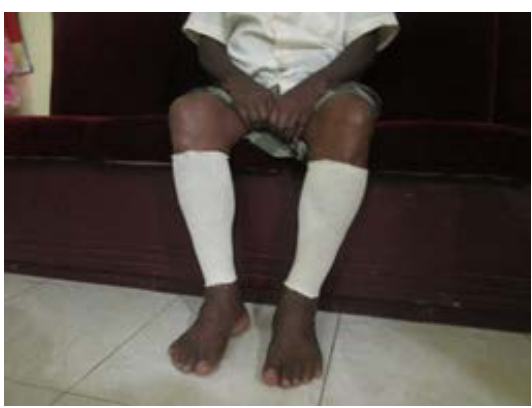

(c)

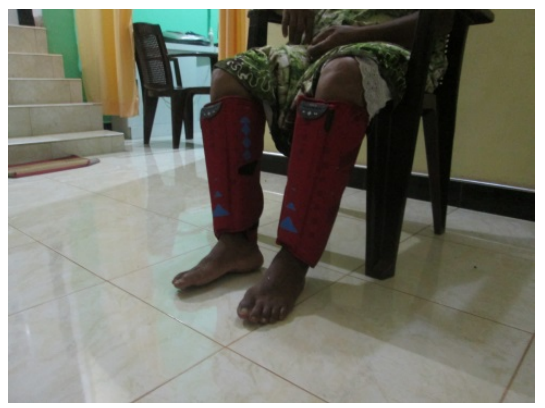

(b)

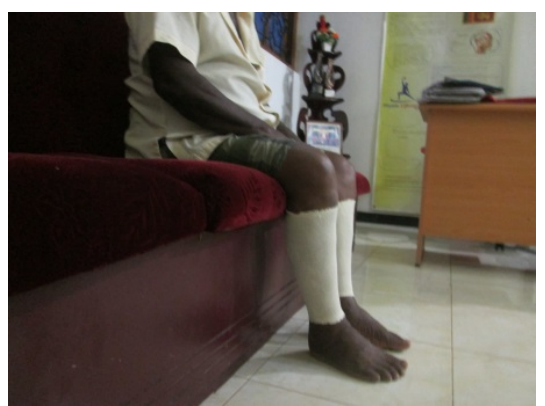

(d)

Application of intermittent pneumatic compression (IPC) using an IPC device. (a) Front view; (b) Lateral view and application of static compression using a static compression garment; (c) Front view; (d) Lateral view.

\section{Appendix 2}

\begin{tabular}{cccc}
\hline \multicolumn{4}{c}{ Risk difference for the improvement of QOL } \\
\hline $\begin{array}{c}\text { Effect measure } \\
\text { Type of intervention }\end{array}$ & $\begin{array}{r}\text { 80\% improvement } \\
\text { in QOL after 4 weeks }\end{array}$ & $\begin{array}{c}\text { Not 80\% improvement } \\
\text { in QOL after 4 weeks }\end{array}$ & Total \\
\hline $\begin{array}{c}\text { Intermittent pneumatic } \\
\text { compression intervention }\end{array}$ & 9 & 8 & 17 \\
Static compression intervention & 0 & 17 & 17 \\
\hline
\end{tabular}

The risk difference for QOL $(\mathrm{RD})=9 / 17-0 / 17=9 / 17$

$=0.529$

Number of patients to be treated $(\mathrm{NNT})=1 / \mathrm{RD}$

$=1 / 0.529$

$=1.89-2$ 